\title{
Erratum to: Post adoption depression
}

Eve S. Fields • Jennifer M. Meuchel • Chiara J. Jaffe •

Manish Jha • Jennifer L. Payne

Published online: 4 September 2010

(C) Springer-Verlag 2010

Erratum to: Arch Womens Ment Health (2010) 13:147-151

DOI 10.1007/s00737-009-0137-7

Unfortunately, the order of the authors had been given incorrectly in our article. The correct order of authors should read:

Eve S. Fields, Jennifer M. Meuchel, Chiara J. Jaffe, Manish Jha, Jennifer L. Payne

as now given above and below.

The online version of the original article can be found at http://dx.doi. org/10.1007/s00737-009-0137-7.

E. S. Fields · J. M. Meuchel $\cdot$ C. J. Jaffe $\cdot$ M. Jha $\cdot$ J. L. Payne $(\bowtie)$

Department of Psychiatry and Behavioral Sciences,

Johns Hopkins School of Medicine,

550 N. Broadway, Suite 305,

Baltimore, MD 21205, USA

e-mail: jpayne5@jhmi.edu 